\title{
Günther Ganster
}

Freier Beruf und Kapitalgesellschaft das Ende der freien Professionen? 



\section{Günther Ganster}

\section{Freier Beruf und Kapitalgesellschaft - das Ende der freien Professionen?}

Eine umfassende juristische Analyse zum scheinbar unaufhaltsamen Siegeszug der Kapitalgesellschaften in den freien Professionen

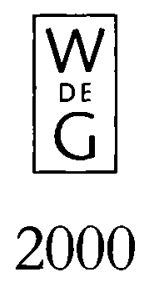

Walter de Gruyter · Berlin · New York 
@ Gedruckt auf säurefreiem Papier,

das die US-ANSI-Norm über Haltbarkeit erfüllt.

Die Deutsche Bibliothek - CIP.Einheitsaufnabme

\section{Ganster, Günther:}

Freier Beruf und Kapitalgesellschaft - das Ende der freien Professionen? : eine umfassende juristische Analyse zum scheinbar unaufhaltsamen Siegeszug der Kapitalgesellschaften in den freien Professionen / Günther Ganster. - Berlin ; New York : de Gruyter, 2000

Zugl.: Frankfurt a. M., Univ., Diss., 1999

ISBN 3-11-016628-3

(C) Copyright 1999 by Walter de Gruyter GmbH \& Co. KG, D-10785 Berlin.

Dieses Werk einschließlich aller seiner Teile ist urheberrechtlich geschützt. Jede Verwertung außerhalb der engen Grenzen des Urheberrechtsgesetzes ist ohne Zustimmung des Verlages unzulässig und strafbar. Das gilt insbesondere für Vervielfältigungen, Übersetzungen, Mikroverfilmungen und die Einspeicherung und Verarbeitung in elektronischen Systemen.

\section{Printed in Germany}

Datenkonvertierung: buslau intercom services, Berlin

Druck: Hubert \& Co., Göttingen. - Bindearbeiten: Lüderitz \& Bauer GmbH, Berlin 